\title{
AS NARRATIVAS DIGITAIS INTERATIVAS E TRANSMÍDIA E A SUA APLICAÇÃO NA APRENDIZAGEM: O STORYTELLING ENCONTROU O CONSTRUIT E PARTIRAM EM BUSCA DO SLIDE
}

\section{INTERACTIVE AND TRANSMEDIA DIGITAL NARRATIVES AND THEIR APPLICATION IN LEARNING: STORYTELLING FOUND CONSTRUIT AND TOGETHER WERE LOOKING FOR SLIDE}

\author{
Vanda de Sousa \\ Escola Superior de Comunicação Social - Instituto Politécnico de Lisboa, Portugal \\ vandamariasousa62@gmail.com
}

\begin{abstract}
RESUMO: Nos dias de hoje, o termo storytelling explode numa miríade de aceções. Para muitos, reporta ao contador de tempos ancestrais; para outros, pode ser a nova descoberta na área do marketing e da publicidade (MILLER, 2014) para outros, ainda, convoca à reflexão o conceito de narrativas digitais (JENKINS, 2001). Aqui consideramos o storytelling enquanto ferramenta de aprendizagem. Como esperamos demonstrar, ignorar o potencial das narrativas digitais como ferramenta de aprendizagem é, a limite, ignorar o potencial da linguagem como performativa da identidade. Para isso, convocámos a experiência da Modelagem Empírica (Empirical Modelling) que tem vindo a ser desenvolvida na Warwick University, Conventry com expressão na conferência CONSTRUIT 2017 e pretendemos demonstrar que a narrativa digital interativa transmídia pode, com sucesso, ser utilizada pela Modelagem Empírica (M.E.) na aprendizagem e literacia tecnológica dos seniores. Para tal, tomámos como referência, o projeto europeu SLIDE. A nossa premissa é que o ato comunicacional e as narrativas digitais sustentam, com sucesso, estes modelos de aprendizagem independendo da idade do aprendente.
\end{abstract}

PALAVRAS-CHAVE: narrativas digitais; storytelling; modelo empírico; literacia.

ABSTRACT: Nowadays, the term storytelling explodes in a myriad of meanings. For many, it reports to ancestral times; for others, maybe it is a new discovery in the field of marketing and advertising (MILLER, 2014). For others, yet, it implies the reflection under the concept of digital narratives (JENKINS, 2006). Here we consider storytelling as a learning tool. As we hope to demonstrate, ignoring the potential of digital narratives as a learning tool is, in the end, ignoring the potential of language as performative of identity. Being so, we have summoned the experience of Empirical Modeling (E.M.) developed at Warwick University, Conventry, namely, the outputs presented at the CONSTRUIT 2017 conference and we intend to demonstrate that interactive digital narrative transmigration can successfully be used by the Empirical Modeling (M.E.) in the learning and technological literacy of seniors. To this end, we have taken as a reference the European SLIDE project. Our premise is that the communicational act and the digital narratives are successful models of learning regardless of the age of the learner.

KEYWORDS: digital narratives; storytelling; empirical modeling; literacy. 
Digam-me e eu esquecerei, ensinem-me e eu poderei lembrar-me, envolvam-me e eu aprenderei.

(Benjamim Franklin)

\section{Introdução}

O desenvolvimento tecnológico, em particular o verificado nas Tecnologias da Informação e Comunicação (TIC), projeta-nos para uma sociedade em rede que ignora barreiras, sejam elas temporais ou geográficas, e assim, abre portas a um novo paradigma comunicacional que, a cada instante e a cada coordenada, se revela global e incentiva um intensivo e extensivo consumo, controlo, construção (e desconstrução) da informação que nos rodeia num fluxo contínuo, promove (e promovendo-se) a participação constante de cada um (e de todos) o(s) indivíduo(s).

Comunicar, do étimo latino, para comungar, partilhar, as estórias são ainda comunicação, uma comunicação anterior à oralidade, primitiva e tribal, mítica e cosmogônica que se tem vindo a atualizar na caminhada do desenvolvimento tecnológico da humanidade, o que nos traz à constatação de que a capacidade de compreender, produzir e entender, que as estórias proporcionam, são constitutivas do ser-se humano, independentemente do paradigma comunicacional em que se viva. O storytelling alcança as novas narrativas digitais transmídia tanto quanto se faz presente nas narrativas tradicionais que veem alterada a sua forma de distribuição e mesmo a forma dos seus artefatos.

Os consumidores vivem, hoje, em constante interação com os conteúdos (JENKINS, 2006), transformando-se, a si mesmos, em consumidores/produtores ou, como Toffler (1970) defende, em prosumers. Ou seja, no novo paradigma comunicacional, o consumidor é interactor, construtor de experiências personalizadas, tendendo a abandonar o seu papel de receptor (espectador) passivo.

O desenvolvimento tecnológico permitiu o ressurgir do storytelling e disseminou-o pelos mais variados campos. O narrar pode ser a nova descoberta na área do Marketing e da Publicidade (MILLER, 2014) para outros, ainda, convoca à reflexão o conceito de narrativas digitais (JENKINS, 2006). Seja qual for a área que o reclame, o storytelling estruturalmente está ligado à cognição, neste sentido, podemos dizer que recordamos e recordamo-nos através de estruturas narrativas, da mesma forma que antecipamos cenários e nos antecipamos através de estruturas narrativas. Por outras palavras, olhamos o mundo e olhamo-nos no mundo através de uma estrutura narrativa, de cada vez e sempre que ligamos acontecimentos (pensamentos e emoções) do passado, presente e futuro assim levando a cabo a nossa estrutura identitária (ESCALAS \& DELGADILLO, 2004).

\section{Storytelling}

À letra, Storytelling remete para o ato de contar/narrar uma história. É uma atividade que pertence ao ser humano e que o próprio ser humano vê como sendo-lhe essencial: através do ato de narrar, o ser humano faz-se futuro (permanece na memória dos que ouvem), olhando o seu passado (recupera as suas próprias memórias) e 
narrando-se no seu presente (RICOEUR, 1976).

$\mathrm{O}$ ato de narrar constrói, então, uma sequência temporal de atos narrados (e narrativos) (METZ, 1974). Isto é, narrar distingue-se de descrever que pressupõe o estático (do que é descrito) e a narrativa (o narrar) pressupõe o dinâmico (cadeia de eventos), pelo que vale dizer que o narrar instala-se cronologicamente (METZ, 1974). No que o contar/narrar se instala na instância do discurso (METZ, 1974). Enquanto discurso, o narrar objetiva um sujeito que narra, assim sendo, a narrativa subtrai-se ao autor posto que este narra para um outro (um não-eu). Assim, além de essencial (no sentido ontológico), o ato de narrar está enraizado na natureza humana (no sentido ôntico), da mesma forma e tanto quanto a linguagem (BENVENISTE, 1966) e/ou decorrendo e dependendo do ser-se humano.

Para muitos autores, o storytelling, o ato de narrar reporta ao contador de tempos ancestrais (SIMMONS, 2006), recuando à arte rupestre (figurativa de eventos que se narram de forma pictográfica), aos mitos, às lendas. Registos orais e memoriais, o ato de narrar, as narrativas, compreendem-se na presença (ou na ausência) do sujeito autoral, independem deste, da mesma forma que dependem do narrador (METZ, 1974).

Neste sentido, Genette (1982) considera três acepções (momentos) na narrativa: o discurso (oral ou escrito) que narra um evento ou uma cadeia de eventos sejam reais sejam ficcionados (GENETTE, 1982); o conjunto das relações entre os eventos narrados (ligação, oposição ou outras); o ato de narrar em si mesmo (GENETTE, 1982).

A narrativa, tal como a conhecemos, mantém e preserva os princípios apontados por Aristóteles em A Poética (ARISTÓTELES, 2008). Assim, a narrativa é una (no sentido que vai do início do acontecimento à sua resolução), decorre por si mesma e sem interferência exterior, centra-se na organização interna dos eventos mimados (ARISTÓTELES, 2008). Por outras palavras, o enredo, o narrado é vivido pelas personagens que dão forma e alma ao conflito; neste sentido, salienta-se a importância da personagem que permite o estabelecimento do ponto de identificação que mantém o receptor preso à narrativa (ARISTÓTELES, 2008).

A ênfase dada à personagem foi estudada por Joseph Campbell (1997) que defende que toda a estória é uma viagem de um herói - uma partida, um caminho, uma aventura, um regresso e uma transformação ou, se se preferir, as doze etapas da viagem do herói: mundo comum, mundo especial, chamada à aventura, recusa da chamada à aventura, encontro com o mentor, atravessar da primeira entrada, testes e inimigos, aproximação à caverna, provação, recompensa, caminho de regresso com o elixir e ressurreição (VOGLER, 2007). As doze etapas constituem o monomito ou estrutura narrativa partilhada por civilizações e culturas, temporal e geograficamente transversais, seguindo o padrão que se reconhece nos mitos ancestrais e que podemos coincidir com as etapas da narrativa: a separação do mundo comum, o confronto e superação dos desafios, o regresso ao mundo comum (CAMPBELL, 1949), coincidindo com a curva dramática clássica aristotélica: primeiro ato (apresentação do conflito), segundo ato (agrava-se o conflito), terceiro ato (resolução do conflito) (ARISTÓTELES, 2008).

Ao momento, pertence-nos tomar consciência do storytelling (das narrativas digitais transmídia) enquanto poderosa ferramenta de aprendizagem. Como demonstraremos, ignorar o potencial das narrativas digitais como ferramenta de aprendizagem é, a limite, ignorar o potencial da linguagem como performativa da identidade. 


\section{Transmídia}

Assim, destacamos a importância do ato comunicacional como fundante da linguagem; demonstramos a linguagem como construtora (performativa) da identidade (individual e/ou coletiva) e o ato de narrar como construtor (performativo) dos contextos socioculturais. Posto isto, evidenciamos que, no atual paradigma de mudança tecnológica, social e cultural, as narrativas digitais interativas e transmídia assumem especial importância nas metodologias de aprendizagem participativas.

$\mathrm{Na}$ sua gênese, a linguagem é um instrumento de comunicação. Expressa a exterioridade e a interioridade (pensamentos e emoções). O uso e o desenvolvimento tecnológico alteram a forma como comunicamos (McLHUAN, 1993): a literacia e a tipografia uniformizaram a linguagem (McLHUAN, 1993) e alteraram as noções de espaço e tempo, dado que a visão deixa de depender quer da audição quer do tato (McLHUAN, 1993).

Benveniste (1966) considera a linguagem como um instrumento (enquanto produção humana com um fim à vista) de comunicação. A linguagem pertence à natureza do homem, no sentido que não podemos pensar o homem antes da linguagem, da mesma maneira que não podemos pensar o homem a inventar a linguagem. Para Benveniste (1966), é na, e pela, linguagem que o homem se constitui como sujeito e subjetividade: o eu é aquele que diz eu.

A consciência de si só é possível se experimentada por contraste: o eu tem consciência que se dirige a um não-eu. Ao dizer eu, postulo outra pessoa, aquele que, sendo como ele é, exterior a mim, torna-se o meu eco a quem eu digo tu e quem tu és para mim. Assim, os pronomes pessoais não se referem a um conceito (não há um conceito que incorpore a totalidade de eus). O eu refere-se ao ato discursivo individual que é pronunciado e, por isso, designa não um conceito, mas a realidade concreta de um falante que se autoproclama falante. Desta forma, com Benveniste (1966), a linguagem é performativa da identidade e da subjetividade.

Para Buber (1982), a palavra é performativa da intersubjetividade porque é dialógica - é através dela que o homem se introduz na existência. No encontro com o outro, o eu torna-se eu e o outro torna-se outro, isto é, um tu. Ou seja, o horizonte de relacionamento interpessoal não é geográfico, mas interpessoal.

Meadows (2003) funda a narrativa no contexto da origem da palavra narrare, do indo-europeu gnarus que significa conhecer. Assim, a narrativa nasce de um acontecimento (real ou imaginário), oral ou textual que é atualizado pelo leitor e pelo ouvinte. A narrativa re-presenta, convoca/evoca, faz presente o ausente. $O$ ato narrativo é a partilha/comunhão de cultura, valores, informações ou conhecimentos que, enquanto digital e transmídia, ainda respeita o postulado aristotélico de sequência dramática de ações (ARISTÓTELES, 2008).

As estórias têm sido a maneira como o ser humano tem promovido a educação, o entretenimento, a divulgação cultural, Eco (1993) salienta que abandonar a narrativa ficcional é abandonar a fórmula que dá sentido à nossa existência, é deixar de responder às questões que orientam a demanda ancestral: Quem sou eu? De onde venho? Qual a minha missão? (VOGLER, 2007) e que Campbell (1997) identifica como arquetípicas e já presentes na mitologia e na cosmologia. 
As narrativas analógicas são lineares, cronologicamente sequenciais (início, meio, fim), e regem-se por uma exposição, um conflito, desenvolvimento, clímax e desenlace (com final aberto ou fechado). Dada a universalidade reconhecida à narrativa, as narrativas digitais transmídia mantêm estas mesmas características, o modo de narrar não muda, o que muda é o mídia utilizado e as suas funcionalidades.

Os desenvolvimentos tecnológicos sucedem-se a uma velocidade vertiginosa e, sobretudo, que continua a catapultar-nos da esfera privada para a esfera pública, gerando um fenômeno que nos transporta para a interação com os outros, humanizando-nos por Acão comum. As narrativas digitais transmídia tornaram-se o nosso lugar existencial em constante e perpétua transformação. Hoje, vivemos e somos nas narrativas digitais interativas transmídia. Por isso, não as podemos ignorar enquanto ferramenta de aprendizagem.

Jenkins (2006) propôs o termo narrativa transmídia, rompendo a ausência de conciliação; Kinder (1991) introduziu a noção de transição midiática; Murray (2003) apresentou o termo hiperserial para expressar estruturas narrativas fragmentadas e dispersas por mídia plurais. A partir do termo narrativa transmídia foi possível fazer convergir os autores no reconhecimento de propriedades, padrões específicos e estratégias de operacionalização (JENKINS, 2006; ASKWITH e GRAY, 2008; DENA, 2004).

O que caracteriza a narrativa transmídia é o facto de ser, sistematicamente, dispersa (fragmentada) por múltiplas plataformas (crossmedia), tendo em vista criar uma experiência de entretenimento unificada (JENKINS, 2006) e imersiva (MURRAY, 2003), gerando um ecossistema totalmente desenvolvido pela própria narrativa. Entrado no sistema narrativo digital, o usuário encontra diferentes, interativas e transmídia narrativas. Assim, não é a narrativa, mas o acesso que diverge do ambiente analógico ou linear. Nas narrativas digitais, o acesso pode ser feito através de diferentes portas de entrada, cada mídia transforma-se numa forma possível de aceder à narrativa, dependendo, inteiramente, da escolha do usuário. Em permanente expansão, independente da vontade do criador e/ou do usuário que se transforma em participante/cocriador (JENKINS, 2006). Isto é, o conteúdo narrativo é desencadeado e ampliado por via do backstory, do mapa de mundo das estórias, perspectivas de outras personagens, participação construtiva na e da narrativa (JENKINS, 2006), aproximando o ato de narrar do ato de jogo (HUIZINGA, 1949).

A narrativa digital transmidiática funda a navegabilidade em classes de módulos e bases de dados. Ecoando o hipertexto, o jogo, a realidade virtual (R.V.) ou ainda a realidade aumentada (R.A.), cabe ao usuário decidir quando e como acede a uma narrativa. Eco (1993) enfatiza que autor, texto e leitor são estratégias discursivas e, ao leitor cabe o papel de cooperador na construção do significado do texto. Com as narrativas digitais interativas e transmidiáticas, liberto da tirania do autor, e acedendo a uma estrutura não linear do hipertexto (Kristeva, 1974) e em palimpsesto (GENETTE, 1982), a narrativa digital transmidiática abre-se à estrutura rizomática (DELEUZE e GUATTARI, 1987).

Assim, as narrativas digitais representam a fragmentação que lhes permite a atitude de crossmídia, num aparente nomadismo transmidiático capaz de gerar um aparente caos. Jenkins (2006) aproxima este caos da geometria computacional representável pelo diagrama de Voronoi (SOUSA, 2017). Ou seja, cada participante é 
equidistante da narrativa global, é coautor da narrativa digital que compartilha a cada momento. A dispersão é aparente porque é participativa, como aparente é a dispersão dos padrões da Natureza.

As narrativas digitais, mesmo que aparentemente dispersas, continuam a travejarse no pacto narrativo, na suspensão da descrença (COLERIDGE, 1817), a mesma que subjaz ao conceito de aprendizagem participativa presente na modelagem empírica e que aqui se descobre como sustentada numa definição formal de narratologia (GENETTE, 1982).

As narrativas digitais (interativas e transmidiáticas ou crossmídia) envolvem-nos e estamos nelas imersos (MURRAY, 2003). Estando presentes no nosso quotidiano, elas invadem o domínio da aprendizagem, desde as aplicações (apps) que usamos nos dispositivos móveis, Redes Sociais Online, na Internet das coisas, em particular, nas Things-to-Think-With. O seu poder de exposição é tão forte que, não raro e como podemos comprovar até mesmo empiricamente, os mais jovens comunicam entre si, nos suportes digitais, já não somente pela via da literacia, mas privilegiando o grafismo (fixo ou animado) dos emojis e giffs. Assim, assiste-se, hoje, à criação de uma nova linguagem, agora mais icónica, com uma nova gramática, uma nova semântica e que antevíamos desde que se reconheceu a chegada da pós-literatura (LYOTARD, 1989).

A questão que nos ocupa é a de compreender como está a ser utilizada esta realidade enquanto ferramenta de aprendizagem. Isto é: estão as narrativas digitais a ser utilizadas nos projetos de aprendizagem dado que a partilha de estórias - storytelling - é uma eficaz ferramenta de ensino/aprendizagem? Em outras palavras: está a linguagem a ser usada na aprendizagem? Fazemo-nos ouvir e ouvimos estórias de forma envolvente utilizando-nos das narrativas digitais interativas e transmídia? A bipolaridade ensino/aprendizagem alicerça-se na bipolaridade eu/tu que a linguagem permite. Já não podemos prescindir deste quase regresso a uma expressão quase cosmogónica e tão icónica que as narrativas digitais representam. Defendemos que a narrativa digital interativa transmídia pode, com sucesso, ser utilizada pelo modelo da Modelagem Empírica (M.E.) na aprendizagem e literacia tecnológica dos seniores.

\section{CONSTRUIT}

Desde os meados da década de noventa do século passado, estas investigações e o trabalho desenvolvido tomaram expressão na conferência CONSTRUIT 2017 (http://construit.org/ CONSTRUIT|making construals as a new digital skill for creating interactive open educational resources). Para ir ao encontro da nossa questão, convocámos a experiência da Modelagem Empírica (Empiral Modelling) que tem vindo a ser desenvolvida na Warwick University, Conventry, com o trabalho dos investigadores Meurig Beynon e Steve Russ, e o trabalho desenvolvido tomaram expressão na conferência CONSTRUIT 2017 (http://construit.org/ CONSTRUIT|making construals as a new digital skill for creating interactive open educational resources).

Se a Warwick University desenvolve o uso da ferramenta digital para a aprendizagem em sentido lato, da nossa parte, na conferência, defendemos que a narrativa digital interativa transmidiática pode, com sucesso, ser utilizada pelo modelo da 
Modelagem Empírica (M.E.) na aprendizagem e literacia tecnológica dos seniores. Para tal, tomámos como referência, o projeto europeu SLIDE (http://www.facebook.com/SLIDE - Storytelling - Learning - in - Digital - Europe - 389295324823558). A nossa pretensão foi evidenciar que é 0 ato comunicacional e as narrativas digitais transmídia que sustentam, com sucesso, estes modelos de aprendizagem.

O projeto CONSTRUIT, dirigido aos jovens, funda-se na Modelagem Empírica que se baseia na acepção da Inteligência Artificial (A.I.) que compreende a construção de artefactos físicos com vista à experimentação como principal via de aprendizagem ao modo do palimpsesto por considerar a experiência estratificadora.

Com raízes no Empirismo Radical, no projeto CONSTRUIT, a modelagem empírica tem vindo a ser desenvolvida privilegiando o agenciamento humano a partir da concepção da linguagem como instinto geneticamente programado e atualizado pela aprendizagem à semelhança de outras capacidades motoras e cognitivas. Assim, a modelagem empírica propõe a aprendizagem como momento experiencial (interação em que cada agente se envolve e que é representado, metaforicamente, por um artefacto físico, tipicamente um computador, suporte das narrativas digitais). Aqui, a aprendizagem baseia-se num padrão de interação entre agentes que ocorre de forma confiável (isto é, em conformidade com e construindo-se como pacto narrativo). De outra forma, o eu e o outro percebem o conhecimento narrado na proposição, de forma objetiva sob a perspectiva de sujeito terceiro (BEYNON, 1999).

Fundamentando-se na suspensão da descrença reconhecida ao pacto narrativo, convoca a experimentação, a criatividade e a imaginação como ferramentas da aprendizagem que surgem da necessidade de aproximar as Humanidades da Computação, abandonando assim o conceito de computador como servidor para o reposicionar, agora, como parceiro do aprendente (BEYNON, MCCARTY, RUSS, 2005) que se torna visível na disseminação das narrativas digitais. Ou seja, no contexto da modelagem empírica, a colaboração entre humanidades e computação é suportada pelo paradigma do mundo aberto em consonância com o qual a interação entre o ambiente e o ser humano surge de modo dialético e formalizado pela linguagem (BEYNON, 1999).

A modelagem empírica caracteriza-se por considerar a linguagem inata, mas também aprendida por modelação empírica; por considerar que a linguagem está informada pela experiência passada e está sujeita a modificações à luz das experiências futuras; por considerar que a linguagem é moderada e está moderada experiencialmente pela interação em que cada sujeito se envolve; e por considerar que a linguagem permite e revela que a escolha do sujeito é pragmática de cada vez que este se integra no seu contexto e não fora dele.

O repto é aceitar que a aprendizagem compreende a capacidade de abstração como qualidade e exercício da inteligência, mas que vai de par com o senso comum, o que permite ancorar a aprendizagem na narrativa digital na qual o aprendente se instala e experimenta, verifica e retifica. Ou seja, visa-se estabelecer uma relação formal entre o mundo e o modelo lógico, de modo que a aprendizagem possa desencadear-se sob a forma de resolução de enigma, ecoando o modelo de imersão e de jogo que enquadram as narrativas digitais.

A modelagem empírica utiliza o construal como artefacto cuja funcionalidade não é dispersa da das narrativas digitais. O construal surge no contexto da teoria Construcionista da Aprendizagem, de acordo com a qual, o estudante aprende através da 
construção de artefactos (físicos ou narrativos), experimentando-os. Esta concepção é a que suporta a recente Teoria de aprendizagem que se sustenta no conceito de Things-toThink-With que significa que a aprendizagem pode ser levada a cabo quando o sujeito estabelece interação com a própria construção. O construal é, genericamente, um objeto que ajuda a explorar e a compreender. Ou seja, o que se pretende é que fique visível o processo de descoberta e não somente a conclusão do processo.

Usando as narrativas digitais, por via da modelagem empírica, torna-se possível criar um ambiente de aprendizagem mediante o reconhecimento de que os conceitos são desenvolvidos e que as conexões entre diferentes situações são estabelecidas como resultado da observação, interação e experimentação repetidas. Replicando o modelo das narrativas digitais, a modelagem empírica cria narrativas objetivas de "terceira pessoa" que ajudam o aprendente a experimentar os cenários possíveis (BEYNON, MCCARTY, RUSS, 2005).

A modelagem empírica começa por se instalar como uma atividade de "primeira pessoa". Isto é, o processo de reconhecimento de semelhanças entre duas (ou mais) experiências é uma atividade da mente, pelo que, os elementos cognitivos primitivos reportam para a "primeira pessoa". Por outras palavras, o aprendente está em diálogo consigo próprio, o entendimento está na fase de construção seguida de reconstrução, à luz da experiência do que constrói, à luz da sua própria narrativa. Na perspetiva da "segunda pessoa", a experiência e a dependência da perceção permitem ir encontrar famílias de observáveis - isto é, os outros que agem de forma congruente com a minha própria forma de agir. Finalmente, há lugar para a construção da perspetiva da "terceira pessoa", constituída pelos elementos da nossa experiência que, empiricamente, parecem ser comuns a todos os outros agentes (BEYNON, MCCARTY, RUSS, 2005).

\section{SLIDE}

Hoje, mais do que nunca, assistimos a um mundo em constante desenvolvimento tecnológico. Vivendo numa sociedade da informação e da comunicação, todos nós, independentemente da idade e da condição sociocultural, temos necessidade de estar atualizados ou de transformar o conhecimento e as capacidades que já possamos possuir. Ser é, mais do que nunca, o exercício de um ato tecnológico que comungamos entre nós. Na esfera pública, gerada pelas redes eletrônicas e pelas redes sociais, descobrimos o que temos, o que não temos, o que somos, o que não somos, ainda em função e relativamente aos outros, ainda num plano tecnológico.

As narrativas digitais estabelecem a estreita ponte entre a esfera pública e a esfera privada da e na nossa vida. Sendo assim, não é avisado negar o acesso das novas tecnologias seja a quem for, a qualquer membro da nossa sociedade. Se os nativos das novas tecnologias têm grande facilidade em lidar com esta realidade, os migrantes das novas tecnologias - idosos e não só - não podem ser esquecidos. Negar-lhes o acesso às novas tecnologias afetará todas as gerações, afetando a comunidade no seu todo, uma vez que eles estarão mais dependentes da população nativa e ativa. Então, é urgente ultrapassar o fosso digital entre gerações, construindo pontes.

Como estabelecemos acima, o ato narrativo faz parte do ser humano, por isso, as narrativas digitais são uma poderosa ferramenta para empreender a tarefa de construção 
daquelas pontes. Mas este é um objetivo que deve ser considerado quando se pretende compreender o presente e o passado seja dos mais idosos, seja dos jovens, seja das crianças e que deve ser considerado quando se pretende aferir e compreender quais são os acontecimentos importantes das suas vidas.

Através da compreensão do ato narrativo como constituinte do ser humano podemos compreender que vias seguir para que se mantenham ativos e integrados no momento digital em que todos vivemos. Assim, torna-se evidente a importância das narrativas digitais transmutadas no processo de storytelling.

A nossa vida é feita de estórias que representam o nosso entendimento quer do mundo quer das pessoas com as quais interagimos, isto é, com a alteridade. As lições de vida guiam o modo como vivemos em sociedade, em comunidade e, como já demonstramos, a tecnologia digital permite-nos partilhar experiências de modo interativo.

A função do velho contador de estórias ficou ampliada, abandonámos o contar a estória que está a ser ouvida para nos posicionarmos, com o storytelling no formato de narrativas digitais, num mais amplo patamar que inclui quatro níveis: 1) Aqui está a estória - que pertence a qualquer médium de transmissão; 2) O que é que estou a ouvir, que estória me está a ser contada? - diz respeito ao envolvimento da audiência com o contador através do médium social de transmissão; 3) Este é o meu mundo e seja bemvindo - é quando e onde o público pode participar; 4) Tome o mundo - o público assume o mundo da estória e começa a criar estórias digitais e interativas (SOUSA, 2017).

A capacidade de construção interativa de uma narrativa digital transmídia torna-a uma importante ferramenta no processo de desenvolvimento do relacionamento intergerações.

O projeto SLIDE (Storytelling - Learning - in - Digital - Europe (https://www.facebook.com/pg/SLIDE-Storytelling-Learning-In-Digital-Europe-

389295324823558/about/) surge para ultrapassar o fosso tecnológico que se instalou entre as gerações nativas e os migrantes das novas tecnologias. Os seniores devem ver resolvidas as suas necessidades cognitivas, sociais e emocionais. Devem ser colocados num círculo alargado, na comunidade e na sociedade. Com o envelhecimento, muitos papeis sociais são deixados para trás, mas outros e novos devem ser assumidos (FINDEISEN, 2013). Aceitar novos papeis requer novos compromissos. Quanto maior o compromisso, melhor a capacidade para aprender, para permanecer independente, ativo, responsável e melhor o entendimento de si mesmo e dos outros (FINDEISEN, 2013).

Pessoas ativas mantêm percepções ativas de si próprias e do envelhecimento, mantendo-se, assim, cidadãos ativos. Na sociedade pós-moderna, na qual vivemos o atual momento de extremo desenvolvimento tecnológico, é improvável que os estereótipos acerca dos idosos sejam abandonados.

Os estereótipos, que apresentam os idosos como estudantes com fracas possibilidades que só estudam para ocupar o tempo, devem ser abandonados. A educação dos seniores é importante para a sociedade no seu todo porque se os seniores podem ter um déficit no que diz respeito aos apetrechos tecnológicos, os jovens têm um déficit de experiência de vida e de valores sociais e culturais (FINDEISEN, 2013).

Todas as gerações têm uma não tangível e invisível herança cultural que deve ser preservada e partilhada. Não há gerações mais importantes do que outras, todas devem ser preservadas e partilhadas, todas intercedem e garantem a coesão social em 
continuidade. As crianças têm um tempo de aprendizagem que é regido pela tentativa e erro. Nos primeiros anos de escola, as crianças estão sob o impacto dos educadores. Na seguinte fase de aprendizagem, e de ensino, as crianças continuam o seu processo de socialização: elas aprendem o que a sociedade espera delas e o que elas podem esperar da sociedade. Com a educação formal, as crianças adquirem ferramentas que as devem motivar no processo de aprendizagem. Na universidade, os jovens estudam livremente os assuntos que mais os motivam.

Hoje em dia, a internet oferece um campo sem fim de aprendizagem que os jovens estão mais aptos a explorar. Jovens adultos e adultos estão subordinados às suas obrigações sociais que surgem de diferentes papeis sociais que desempenham. Quando alcançamos a idade adulta, recordamos a infância como um tempo de felicidade, um tempo em que somos guiados pela família, um tempo em que sonhamos com o que queremos ser quando formos adultos e a sociedade em que desejamos viver a nossa vida (FINDEISEN, 2013).

Se considerarmos o conjunto do curso da nossa vida, podemos ver que há uma distinção entre aprendizagem, educação e escolaridade. Aprendizagem significa mudar/moldar um indivíduo em conformidade e por ação e influência de fatores externos. Só uma parte da aprendizagem é educação. Em contrapartida, a escolaridade é uma parte da educação (FINDEISEN, 2013). Enquadrados na sua experiência social e de vida, os seniores definem que objetivos desejam para a sua aprendizagem, o que desejam aprender. Quando trabalhamos na educação de adultos, devemos ter como meta promover uma equidade social e cultural que vise eliminar o fosso tecnológico, promover a capacidade de diálogo e intercâmbio geracional (FINDEISEN, 2013).

\section{Considerações finais}

Estamos a viver um momento de fragmentação social e cultural, no qual as gerações se posicionam em temporalidades diferentes. É urgente eliminar o fosso que se instalou e que tende a separar, cada vez mais, os jovens e os seniores. A sociedade está a caminhar, cada vez mais, para o risco de se tornar uma distopia se persistirmos na nossa atitude de ignorar o fosso geracional no que diz respeito ao desenvolvimento tecnológico.

Como demonstrámos, a linguagem é essencial ao homem. Na linguagem e pela linguagem, o homem toma consciência do seu eu, de si mesmo e, assim, abre espaço para a troca comunicacional.

Que o ato narrativo é ancestral prova-o a magia da poesia que é mágica de cada vez que, em conformidade com as suas raízes, tenta mudar a forma como percebemos o mundo. A poesia enquanto ato primevo de narrativa, molda a nossa percepção do real que nos envolve, na sua forma mais primitiva ela revela-se um sistema de armazenamento e transmissão de saberes. A palavra descreve o acontecimento ou o objeto, mas a palavra poética invoca e ensina. Ao provocar uma emoção, a palavra poética primeva corre riscos, o tipo de risco que faz com que os que a ouvem (os que as comungam nas narrativas digitais) se sintam verdadeiramente desconfortáveis e abertos a sugestões e reprogramações (aprendizagens), cúmplices num processo criativo da sua autoformação, enquanto homens e mulheres que se sabem projetos infinitos auto 
abortados - os únicos nascidos com a consciência da sua própria morte - feitos de carbono, tendo cometido o irremediável erro de se erguerem sobre dois pés sobre 0 planeta (PATERSON, 2004).

Através da narrativa, agora e para nós, digital, o homem acede a compreender-se a si mesmo, aos outros e ao real que o rodeia. O desafio é garantir que a narrativa (digital) assegura e contribui para a coesão social e cultural.

Nas narrativas digitais interativas procuramos uma experiência imersiva que é muito semelhante à que temos quando mergulhamos no oceano, enquadrando assim a experiência narrativa digital interativa (Storytelling) na experiência possibilitada pelo construal na modelagem empírica, talvez se possa compreender que a sensação uterina provocada pela imersão (Sousa, 2017) legitima que as narrativas digitais se ergam para transpor as barreiras, tal como o projeto SLIDE tem tentado fazer.

As novas tecnologias separam as gerações, mas também podem ser usadas para as unir. As narrativas digitais interativas e transmídia (Storytelling) podem representar uma forte ferramenta para a aprendizagem mediante a sua conceção de Construal, como o demonstra o projeto convocado - CONSTRUIT -, como podem representar uma forte ferramenta para a inclusão geracional, como o demonstra o projeto SLIDE.

A salientar temos que as narrativas digitais enquanto ferramenta (urgente) de aprendizagem podem ainda contribuir para a desconstrução de velhos e trágicos estereótipos sociais e culturais. Comprova-o o facto de narrar ser ancestral na estória da humanidade. Desde os tempos imemoriais, houve sempre alguém disposto a começar... Era uma vez... Portanto, venha daí... Vamos construir a nossa estória (História).

\section{Referências}

ARISTÓTELES. 2008. Poética. Lisboa: Fundação Calouste Gulbenkian.

ASKWITH, I. \& GRAY, J. 2008. "Transmedia Storytelling and Media Franchises", in Robin Anderson \& Jonathan Gray (Eds), Battleground the Media (pp. 519-528). United States of America: Greenwood Press.

BENVENISTE, E. 1966. Problèmes de linguistique générale. Paris: Gallimard.

BEYNON, M. 1999. "Empirical Modelling and the Foundations of Artificial Intelligence". Department of Computer Science University of Warwick, UK.

BEYNON, M.; MCCARTY, W.; RUSS, $\quad$ S. 2005. In https://www.researchgate.net/publication/31458408_Human_Computing-Modelling_with_Meaning.

BUBER, M. 1982. Do diálogo e do dialógico. São Paulo, SP: Perspectiva.

CAMPBELL, J. 1997. The hero with a thousand faces. Princeton, Princeton University Press. 
DELEUZE, G. \& GUATTARI, F. (1987). A Thoushand Plateaus: Capitalism and Schizophrenia. Minneapolis: University of Minesota Press.

DENA, Christy. 2004. Current State of Cross Media Storytelling: Preliminary Observations for future design. Apresentado em Crossmedia communication in the dynamics knowledge society networking session em European Information Systems Technologies (IST) Event, 15 Novembro. Holanda: IST. p. 1-11.

ECO, U.1993. Leitura do Texto Literário: Lector in Fabula. Lisboa: Presença.

ESCALAS, J.; DELGADILLO, Y. .2004. "Narrative Word-Of-Mouth communication: Exploring memory and Attitude Effects of Consumer Storytelling", advances in Consumer Research Volume 31, pp: 186-192.

FINDEISEN,

D. 2013.

"Third_Age_University_Stereotypes_Prejudices_Old_Age_Discrimination_Where_Do_We_Stand" in

D. https://www.academia.edu/3894247/Dušana_Findeisen_Slovenian_Third_Age_University_ Stereotypes_Prejudices_Old_Age_Discrimination-_Where_Do_We_Stand

GENETTE, G. 1982. Palimpsests: La Litettérature au Second Degrée, Paris: Seuil.

HUIZINGA, J. 1949. Homo Ludens - a study of the play-element in culture. London, Routledge \& Kegan Paul.

JENKINS, H. (2006). Convergence Culture: Where Old and New Media Collide. Nova Iorque: New York University Press.

KINDER, M. 1991. Playing with Power in movies, television, and vídeo games. University of California Press. PP 5-277.

KRISTEVA, J. 1974. La Revolution du Language Poétique. L'Avantgarde à la Fin du Dixneuviéme Siècle: Lautréamont et Mallarmé. Paris: Seuil.

LYOTARD, J.P. 1989. A Condição Pós-Moderna. Lisboa: Gradiva.

MCLHUAN, M. 1993. Os Meios de Comunicação Como Extensões do Homem. São Paulo: Cultrix.

MEADOWS. 2003. Pause \& Effect.The Arte of Interactive Narrative. USA: New Riders.

METZ, C. 1974. Film Language: A Semiotics of the Cinema. The University of Chicago Press.

MILLER, C.H. 2014. Digital Storytelling: A Creator's Guide to Interactive Entertainment. New York: Focal Press. 
MURRAY, J. 2003. Hamlet no Holodeck: o futuro da narrativa no ciberespaço. São Paulo: Itaú Cultural-UNESP.

RICOEUR, P. 1976. Teoria da Interpretação: O Discurso e o Excesso de Significação. Edições 70, Lda.

SOUSA, V. 2017. "Interactive transmedia vs. voronoi diagram expressions" EUROSIS ISBN 978-9077381-97-7 SCIFI-IT '2017 April - Bruges, Belgium.

TOFFLER, A. 1970. O Choque do Futuro. Lisboa: Livros do Brasil.

VOGLER, C. 2007. The writer's journey: mythic structure for writers. Ann Arbor: Sheridan Books.

Webgrafia dos projetos:

CONSTRUIT

(https://warwick.ac.uk/fac/sci/dcs/research/em/construit/conference/programme)

\section{SLIDE}

(https://www.facebook.com/pg/SLIDE-Storytelling-Learning-In-Digital-Europe389295324823558/about/).

Recebido em dia 31 de dezembro de 2018.

Aprovado em dia 18 de março de 2019. 